We need to be wary of recommending to our colleagues in district general hospitals high technology procedures that are often not available and that require skill. Eighty one years ago James Mackenzie wrote in the preface of his marvellous book": "In routine practice it is not usually necessary to take graphic records. If one is trained to make careful and minute observations by the ordinary methods, and to have these checked by graphic records, one can ultimately acquire the power of recognising the majority of movements of the circulation without graphic records." Partly out of necessity but also out of kindness to our patients we need to remember his advice. Technology has made possible most of the spectacular advances in cardiology and cardiac surgery in the past 35 years. Once we have learnt from it, however, we can often dispense with it, particularly if we wish to train our successors to be good doctors and not just high technologists.

PETER CARSON

City General Hospital,

Stoke on Trent ST4 6QG

I Caplin JL. Acute right ventricular infarction. BrMed $\mathcal{F}$ 1989;299. 69-70. (8 July.)

2 Winner S, Boon N. Critical problems with temporary pacemakers prior to permanent pacing. $\mathcal{I} R$ Coll Physicians Lond 1989;23:161-3.

3 Mackenzie J. Disease of the heart. 1st ed. London: Henry Frowde and Hodder and Stoughton, 1908:viii.

\section{Effects of burglary on elderly people}

SIR, - The work of Dr D O'Neill and colleagues parallels a survey we carried out in spring 1988 . We assessed 116 consecutive admissions, excluding 25 subjects who came from elderly persons' homes, who were too ill to respond, or who were cognitively impaired; 43 were men (age range 56-92, mean 76 years) and 48 women (age range 69-97, mean 83 years)

Of the 91 patients surveyed, 38 had suffered a burglary at some time; nine had had more than one burglary. The two groups were compared using the $\chi^{2}$ test.

In the burgled group there were twice as many women as men $(\mathrm{p}<0.05)$. The type of property seemed to influence the risk of burglary: more of the properties in the burgled group were owned by landlords and fewer were sheltered houses or housing association properties $(p<0 \cdot 01)$. Experience of burglary was not related to age or house occupancy. Thus, living alone did not seem to be a risk factor for burglary, in contrast to the findings of O'Neill and colleagues.

We too looked at security but found no difference either in the use of security equipment or in the ability to recall advice received on crime prevention; the most frequently named source of such advice was the police.

Half of the elderly people who had been burgled were present at the time of the break in, but only three were injured, which suggests that crimes were fraudulent entries and petty break ins.

One person was admitted to hospital as a direct consequence of the burglary, and five others had suffered burglaries less than one month before admission. In addition, many patients reported that fear of crime left them too frightened to leave their homes: in effect a self imposed house arrest. ${ }^{2}$

Thus we found that elderly people are vulnerable to burglary. Such events may be "petty" crime but may have a devastating effect on their lives.

We suggest that elderly people are not using the protective measures that are available to them and that present methods of education and advice on crime prevention are inadequate. Advice must be given by those in close contact with elderly people, who may then persuade them on a personal and individual basis.

Although health and social service staff in contact with the elderly must support them through their fears of falling victim to crime and help them if their fears are realised, we have an equally important role in education and helping them to protect themselves.

C A CHEW

usholme Health Centre,

Manchester M14 5NP

C M CHESHIRE

Manchester Royal Infirmary,

Manchester M13 9WL

I O'Neill D, O'Shea B, Lawlor R, McGee C, Walsh JB, Coakley D. Effects of burglary on elderly people. Br Med $\mathcal{F}$ 1989;298: 1618-9. (17 June.)

Goldsmith J, Tomas NE. Crimes against the elderly: a continuing national crisis. Ageing 1974;236: 10-3.

\section{Acute cerebral oedema induced by methotrexate}

SIR, - Dr S Ellis ${ }^{1}$ disputed the interpretation of the case reported by Drs P J Hughes and R J M Lane of acute cerebral oedema following intrathecal methotrexate, ${ }^{2}$ and in particular their claim that the accompanying intracerebral haemorrhage was merely coincidental. Drs Hughes and Lane answered these criticisms, ${ }^{3}$ but I would offer another possible explanation in the light of a case seen here recently.

A 63 year old man with non-Hodgkin's lymphoma had a cauda equina syndrome, and cytological examination of his cerebrospinal fluid showed lymphoma cells. He was given $10 \mathrm{mg}$ of methotrexate intrathecally, and two days later he complained of a headache and developed acute dysphasia and a right hemiparesis. Computed tomography of his head showed some effacement of the sulci in the left parietal region and the contrast enhanced films suggested a superior sagittal sinus thrombosis ("black triangle sign"). This was confirmed by digital subtraction angiography. His symptoms and signs gradually resolved over the next three weeks or so and there was no recurrence over the remaining six months of his life. Intrathecal methotrexate commonly causes a chemical meningitis leading to headache and neck stiffness ${ }^{+}$and I presume that this inflammation of the wall of the sinus or its feeding cortical veins contributed to the formation of thrombus.

Acute thrombosis of the superior sagittal sinus may lead to swelling of the cerebral hemispheres and to haemorrhagic venous infarction. This may be an alternative explanation for the clinical and radiological features described by Drs Hughes and Lane, and one which would satisfy Dr Ellis's plea for the application of Occam's razor.

T P FNEVOLDSON

Department of Neurology,

St Thomas's Hospital

London SE1 7EH

1 Ellis SJ. Acute cerebral oedema induced by methotrexate. Br.Med f 1989;299:122. (8 July.)

2 Hughes PJ, Lane RJM. Acute cerebral oedema induced by methotrexate. BrMed F 1989;298:1315. (13 May.)

3 Hughes PJ, Lane RJM. Acute cerebral oedema induced by methotrexate. Br Med f 1989;299:123. (8 July.)

+ Bleyer WA. Neurologic sequelae of methotrexate and ionizing radiation; a nèw classification. Cuncer Tréat Rep 1981;65 (suppl 1):89-98.

\section{Trends in paediatric medical admissions}

SIR, - We reject Professor John O Forfar's proposal of ready recourse to early hospital admission ${ }^{1}$ as a cost effective means of reducing childhood mortality and morbidity. The decision to admit should be based on predictive judgment of costs risks, and benefits. Unnecessary admission is costly in terms of money and skills and may be harmful-for example, it may cause family disruption, cross infection, accidents, assaults, and iatrogenic disorders and may undermine the confidence of mothers and general practitioners to cope with minor problems. Benefits of early diagnosis in the minority of severe illnesses can be achieved more cheaply through prompt access to an experienced paediatrician and willingness to undertake frequent clinical review as necessary; happily most suspicion of serious disease is misplaced.

In practice decisions to admit are often based on an interaction among the liberality of the policy for admission, the ability of the referring doctor, pressure from parents, and the availability of an experienced doctor to screen admissions. Three years ago we realised that our liberal policy for admission was having adverse effects; and a tighter screening and follow up policy has enabled one of our three children's wards to be put to better use for adults.

Dr J D Bland ${ }^{2}$ pointed out that in Norway the salary of a consultant paediatrician working a shift system similar to that described by Dr J Davies and colleagues in Grimsby ${ }^{3}$ was paid for if one admission each day was avoided. We have found that the screening of a proportion of admissions by a consultant over the past two and a half years has been cost effective and safe. It can be demanding in terms of availability, taking a careful history, performing examinations, discussion with parents, referral back to the general practitioner, and follow up where indicated. Not surprisingly, many junior doctors are insufficiently experienced or motivated to make such decisions.

In summary, admission to hospital is often an expensive, simply initiated, but protracted method of obtaining a second opinion, and we should continue to look for better ways of recognising and dealing with those sick children who will not benefit and may suffer from hospital admission.

J L P HUNTER J M DAVIES B REYNOLDS

District General Hospital,

Grimsby: Health Authority,

Grimsby DN33 2BA

1 Forfar JO, Trends in paediatric medical admissions. Br Med $\mathcal{f}$ 1989:298:1711. (24 June.)

2 Bland JD. Advantages of consultants on call: the Norwegian experience. Br.Med f 1989;298:1529. (3 June.)

3 Davies JM, Hunter JLP, Reynolds B. Shift working for consultants. Br.Med J 1989;298:1037. (15 April.)

\section{Sensible guidelines on immunisation}

SIR,-Clearly concern about possible contraindications to pertussis vaccine continues to depress the immunisation rate. ${ }^{1.3}$ At long last an authoritative group of people in Britain has had the courage to produce sensible guidelines for the immunisation of children against pertussis.

The recently published British Paediatric Association manual suggests that all children should be immunised except those suffering from an acute febrile illness and those who have had a severe local or general reaction to a prior immunisation, including pertussis. For all other children the benefits of immunisation outweigh the risks. Neurological disease, neonatal cerebral problems, and a personal or family history of convulsions or epilepsy are no longer regarded as contraindications, but the parents of children with such a personal or family history should be instructed to use paracetamol and avoid wrapping the child in too many clothes if fever develops. (There is, of 